\title{
¿Por qué traducimos?
}

La primera vez que me topé con el nombre de Alice Stone Blackwell fue en un capítulo de Main Currents of Spanish Literature, un libro publicado en 1919 y escrito por Jeremiah D. M. Ford, intelectual del panamericanismo y chair del departamento de lenguas romances de Harvard por más de treinta años. En medio del capítulo de Ford dedicado a los "puntos altos de la literatura hispanoamericana" se encontraba una línea que hablaba de las "felicitous versions" creadas por Miss Blackwell de los poemas de José Santos Chocano. Así decía: "Miss Blackwell”. Me imaginé una mujer con el pelo recogido sobre la nuca, sentada con sus faldones largos, tomando té a la luz de una ventana junto a una mesa llena de libros y papeles, lápices y plumas. Es decir, vi a Emily Dickinson, o la imagen que tengo de Emily Dickinson, quien, por cierto, escribía sobre todo de noche, a la luz de las velas. Buscando esa imagen hice la primera búsqueda -en internet- sobre Alice Stone Blackwell, en la cual alcancé a vislumbrar lo que después confirmaría la investigación en sus archivos, sus papeles: Alice Stone Blackwell estaba lejos de ser una mujer circulando solo en su hogar, en su jardín, en el espacio de una hoja de papel o en sus propios textos (y al decir propios me refiero a los que producía directamente y a sus versiones, traducciones de textos ajenos). Alice Stone, Miss Blackwell, además de ser traductora fue una mujer políticamente comprometida, radical, sufragista, editora, interlocutora de los hombres de Harvard que buscaban a principios del siglo XX explicar la literatura latinoamericana y, a través de ella, la "mente" de la región.

Blackwell no era Dickinson. Su escritura tampoco era la de la poeta de Amherst. Yo, que entretenía la idea de traducir, me prendé más de su figura, de sus motivos, que del resultado de sus traducciones, que me parecieron en un principio demasiado marcadas por el paso del tiempo. Pero también muchos de los originales en español tenían la marca de los años y poco a poco me empecé a encariñar con los intentos de Blackwell por buscar una música propia o una que evocara al original o por rendirse de antemano con algunos poemas y entregar sus versiones en prosa para respetar y transmitir el espíritu, el contenido. Me intrigaba que declarara que existían traductores excepcionales, capaces de llevar la música de un poema de una lengua a otra, y que se contara, sin problemas, entre los que quedaban fuera de esa categoría.

Luego, comencé a estudiar también a Isaac Goldberg, a entender sus complejidades, como traductor, escritor, crítico y hombre formado en letras y literatura. Lo que más me atrajo de él desde un principio fue su intento por hacer de la práctica de la traducción una profesión y ver el fracaso de ese intento. Me fascinó encontrar en su correspondencia con agentes y escritores su deseo de 
ganarse la vida haciendo una de las cosas que más disfrutaba y ver cómo en el proceso produjo traducciones mal hechas o tradujo textos que jamás hubiera elegido si hubiera sido por él. Es decir, me sorprendió ver en él, en su práctica de comienzos del siglo XX, los mismos impulsos, los mismos problemas de los traductores de hoy, pero, sobre todo, me atrapó ver cómo modulaba su intento de profesionalización de la traducción dentro del mismo contexto, con los mismos marcos, con límites similares, que Blackwell. Respuestas disímiles para condiciones tan parecidas, producidas por deseos dispares, lejanos el uno del otro.

Casi al mismo tiempo que comencé a leer sobre estos traductores encontré esa reseña de Grant H. Code sobre Studies in Spanish American Literature, de Goldberg, en la revista Poetry y me sorprendió leer esa rabia contra las versiones de Blackwell. ¿Eran tan marcadamente antiguas? ¿Tan malas? ¿Me estaba perdiendo de algo por leer la reseña y las traducciones desde mi tiempo, mis condiciones? Pronto entendí que la clave estaba ahí, en la reseña misma, en sus alabanzas a la transparencia de las versiones de Goldberg, hechas por el traductor así al pasar, meramente como ilustración del contenido de versos que había usado directamente en español a lo largo de su estudio. Code abogaba por la invisibilidad del traductor como condición de una buena traducción, pero, sobre todo, pedía la invisibilidad de Blackwell, de su género, de su ser mujer traductora, radical, de no ser formada institucionalmente en la lengua o la literatura que había elegido traducir. Porque también esa rabia de Code, era atravesada por la libertad de Blackwell, por su deseo y voluntad, su amor, su pasión, en otras palabras, por su ser amateur. Poco a poco estas lecturas sobre Blackwell, sobre Goldberg, sobre esta reseña, se fueron transformando en preguntas, en temas, en ideas que llevaron a otras, a una red de inquisiciones sobre la práctica traductora y su relación con el amateurismo. Así apareció la necesidad de entender el contexto histórico, político, cultural, de la escena de traducción en la que Blackwell y Goldberg desarrollaron su trabajo, para así darle un fondo a toda esta problemática. De todas estas preguntas y temas que alimentaron este libro quiero volver aquí, en el cierre, a dos en particular.

\section{¿Qué es una buena traducción?}

0 , ¿qué es una mala traducción? La pregunta me lleva a una de las características más discutidas de la traducción ya sea en críticas académicas, reseñas de periódicos, pautas editoriales, conversaciones comunes: la fidelidad. Se pide que un traductor sea fiel al autor, a su voz, al texto escrito en la lengua extranjera, pero ¿qué significa ser fiel en una traducción? Para algunos, como Code, la fidelidad está en la invisibilidad, la transparencia, en el quitarse del camino para que se cree la ilu- 
sión de que el lector está en frente del autor. Code encuentra esa fidelidad en las traducciones literales que hace Goldberg para su Studies in Spanish American Studies. Pareciera que Code no está al tanto de los peligros de la literalidad, que me hacen pensar en Hölderlin y en lo que escribe Anne Carson sobre él:

The deadly literalism of the line is typical of him. His translating method was to take hold of every item of the original diction and wrench it across into German exactly as it stood in its syntax, word order and lexical sense. The result was versions of Sophokles that made Goethe and Schiller laugh aloud when they heard them. Learned reviewers itemized more than a thousand mistakes and called the translations disfigured, unreadable, the work of a madman (Carson 2016: s/p.).

Aquí aparece la literalidad como locura, como pérdida de sentido y, por lo tanto, como infidelidad para con el texto primero. Se lee tan de cerca, se reproduce tan apegadamente el material a traducir que se pierde la lógica de lo escrito. Algo parecido pasa, sin llegar a los extremos de las traducciones de Hölderlin, cuando en 1865 Francis W. Newman, helenista de la Universidad de Londres, publica la traducción de la Ilíada que le había llevado años y que reproducía lo más detalladamente posible las particularidades del griego antiguo, resultando en un inglés extraño, casi extranjero. Efraín Kristal cuenta que Matthew Arnold un poeta y profesor de Oxford, organizó una serie de conferencias para proclamar que la traducción del experto Newman era pésima: “Arnold reconocía que Newman era un erudito del griego clásico, pero señalaba que las buenas traducciones requerían de algo más...” (Kristal 2013: 5) ${ }^{1}$. Según Arnold, la rendición de Newman, su apego tan erudito a la fuente, había vuelto confuso y torpe el texto claro y ágil de Homero, reflejando, en su fracaso, el desencuentro de dos lenguas. Seguramente Arnold hubiera estado de acuerdo con Walter Benjamin, quien algunas décadas más tarde escribiría que "Any translation which intends to perform a transmitting function cannot transmit anything but information -hence, something inessential. This is the hallmark of bad translations" (Benjamin 1988: 69).

Las malas traducciones aparecen, entonces, despojadas de lo esencial, lo que nos lleva a preguntarnos qué es lo esencial, qué se esconde entre las líneas de una "buena” traducción. ¿Es el alma de la que hablaba Blackwell?, ¿la mente que buscaban Goldberg y los demás intelectuales cercanos al panamericanismo? ¿Es eso esencial de la traducción lo que permite "conocer” al otro, llegar a él, más allá de los datos y la información que buscaba el panamericanismo? Esa cualidad esencial de la traducción sería transmisible entonces a través de una tra-

1 Como dice Kristal, esta discusión entre Newman y Arnold después sería vital para muchas de las ideas que Borges trabajará sobre la traducción. Sobre esto volveremos un poco más adelante. 
ducción lograda, exitosa, una que hace trizas la noción de la literalidad como equivalente a la fidelidad. La noción de fidelidad se tambalea, se relativiza. Por ejemplo, pensemos en un par de buenas, clásicas, traducciones, como la que Borges hizo para Sur de la última página del Ulises sin haber leído siquiera el resto del libro de James Joyce. Cuenta Patricia Willson que Borges mira el texto, lo lee por aquí y por allá, y luego arranca sin historia previa, con esa única página que hasta hoy se conoce como el Ulises de Borges. O pensemos en el Remembrance of Things Past de C.K. Scott Moncrieff, que no solo borró de su título las pérdidas de Proust sino que creó un texto más delicado y poético que el original, una versión que ha perdurado en el tiempo como una obra maestra en sí misma². Aunque tenga sus detractores, para muchos lectores ingleses esta traducción ha hecho que el nombre del traductor se haga inseparable del autor, resultando en algo así como 'el Proust de Scott Moncrieff'. O revisemos el comienzo de una traducción más reciente, recibida bien por algunos y mal por otros, la Antígona de Anne Carson ${ }^{3}$.

[Enter Antigone and Ismene] Antigone: We begin in the dark and birth is the death of us Ismene: Who said that Antigone: Hegel Ismene: Sounds more like Beckett Antigone: He was paraphrasing Hegel Ismene: I don't think so (Carson et al. 2012: s/p.).

Aquí la fidelidad entra en un terreno intangible, el territorio de lo esencial, si queremos llamarlo así. Los traductores leen e interpretan un texto, como un actor interpreta un papel, como un músico interpreta una partitura. Lo hacen de acuerdo a su formación, su experiencia, sus vivencias, es decir, según su subjetividad, como dice la definición de Esther Allen de traducción literaria. Lo que hacen los traductores, lo que producen, son textos suyos, fieles en más de un sentido al texto, pero fieles también al ser traductor, al deseo que los motiva, los mueve, a esa danza de tres, a esa rueda triangular que lleva a publicar, circular, entregar esos textos que reflejan de alguna manera los textos iniciales escritos en lenguas extranjeras. Textos a los que se enfrentan sin ese miedo socrático del que habla Göransson, sin la ansiedad de entregar el cuerpo, la escritura a esas voces que vienen de afuera. Pero estos traductores que acabamos de mencionar, ¿no son acaso parte de los traductores extraordinarios de los que hablaba Blackwell? T.S Eliot dijo en la introducción de 1928 a los Selected Poems de Pound:

2 Jean Findlay cita en su libro sobre Scott Moncrieff una carta de Joseph Conrad al traductor, en la que Conrad decía: "I was much more interested and fascinated by your rendering than by Proust's creation. One has revealed to me something and there is no revelation in the other..." (Findlay 2015: 2).

3 Ver Staff (2012). 
As for Cathay, it must be pointed out that Pound is the inventor of Chinese poetry for our time. I suspect that every age has had, and will have, the same illusion concerning translations, an illusion which is not altogether an illusion either. When a foreign poet is successfully done into the idiom of our own language and our own time, we believe that he has been 'translated'; we believe that through this translation we really at last get the original ... (el énfasis es mío, Williams 2009: 147).

El Ulises de Borges, el Proust de Scott Moncrieff, la Antígona que vuelve con Carson, tienen entonces esa aura de traducción genial, exitosa, original. Es su valor estético el que les da el pase de originalidad, el que, de alguna manera, los convierte en textos primeros. Ahora, ¿cómo leer un texto?, ¿cómo interpretarlo y traducirlo si no se tiene la libertad, la escritura o la autoridad de estos tres traductores que mencionamos?, ¿cómo hacerlo sin perder "al otro", su cultura, sus valores, algo de la lengua que originó la traducción? Supongo que de la misma manera, interpretando, dejando que la experiencia, la formación y la vivencia aparezcan en la lectura y en la traducción. Dejando que la interpretación y la subjetividad terminen con la idea de que el traductor es invisible, por mucho que las condiciones de la práctica -los nombres que no aparecen en las portadas, los pagos exiguos o inexistentes- dicten lo contrario. Traer ese texto que de alguna forma se desea, sin olvidar que viene de un contexto determinado y que desde allí llega al nuestro.

Ahora, claro que hay formas de traducir, distintas estrategias para interpretar un texto. Borges, en su Prólogos, decía que la traducción es "un sorteo experimental de omisiones y énfasis” (Kristal 2013: 7), es decir idas y venidas, elecciones, entre momentos de literalidad -que según Borges pueden producir hallazgos mágicos- y momentos donde se hace necesario evitar la oscuridad o las torpezas de un texto fuente. Tanto Blackwell como Goldberg jugaron con los silencios y los énfasis en sus traducciones. En su intento por contar Latinoamérica crearon originales que se sostenían por sí mismos, que se pueden criticar como piezas únicas. En otras palabras, podemos decir que ellos al traducir buscaban el valor estético en sus versiones, algunas veces con mejor resultado que otras y, en el caso de Goldberg, dependiendo del compromiso con el texto. No obstante, como hemos dicho a lo largo de este estudio, una traducción no funciona sin su contexto histórico, político, cultural, social, por lo tanto, su valor estético se pone siempre en relación con algo que va más allá del desentrañar las entrelíneas del poema o del cuento o novela a traducir. Este algo más, que también podemos pensar como parte esencial de la traducción es el sentido, el propósito que acompaña a la práctica cuando en ella ha intervenido la elección, la voluntad del traductor. En el caso de Blackwell y Goldberg ese deseo pasaba por incluir a otros intelectuales y artistas del margen en una comunidad hemisférica de mentes, de almas, y también por la idea de contribuir en la construc- 
ción de una idea de mundo más amplia, inclusiva. Pero el propósito que puede ser aun más radicalmente político también puede ser estético, como por ejemplo se da en las traducciones de Borges o de Victoria Ocampo para Sur, las que según Willson tuvieron como función el renovar el panorama estético de la literatura argentina de la época. Para resumir estas ideas podríamos ensayar una respuesta y decir que una buena traducción, entonces, es aquella que produce originales, textos dueños de su propio valor estético y que además son portadores de esencia, de la entrelínea de la escritura primera y del propósito establecido por el deseo del traductor.

\section{Trabajo intangible}

Si hablo tanto de deseos y esencias es porque parto de la base de la principal propuesta de este estudio, es decir, de que todos los traductores literarios somos amateurs: trabajadores que entregan su labor por poco o nada de dinero, que se mueven con cierta libertad alrededor de las instituciones pertinentes, que se preparan, se forman, roban tiempo del tiempo libre para un trabajo que nace del deseo y de la pasión y que entrega placer, pero muy raramente sustento. Trabajadores en el margen de la cadena de producción, en el margen del campo literario también. A veces, incluso, para poder seguir traduciendo hay que suspender tal vez el deseo y aceptar algún texto que no fascine, pero que hace de puente con otros que sí lo harán. Michael Hofmann explica así su forma de relacionarse con el material que traduce:

Whatever the contracts say, I like to think I'm not "labor for hire." I never learned to park my opinions outside like a pair of shoes - I kept my likes and dislikes. There are things that interest me, and things that interest me less. To translate a book is an immense effort of affection. There are stories and sometimes entire writers that seem important to me, and others that really don't ... Over time you of course lose some of your freedom (el énfasis es mío, Hofmann 2017).

Cariño o afecto y esfuerzo, dos coordenadas claves de la producción de traducciones que intentan interpretar sentidos, culturas y esas cualidades esenciales de la literatura, del propósito de la traducción. A eso nos aplicamos los traductores, desde Blackwell y Goldberg, y tantas, tantos, antes que ellos, y después de ellos. Omitimos, enfatizamos, probamos voces, investigamos, a veces nos atrevemos a innovar y siempre, aunque sepamos que no va a suceder, esperamos el momento en que por alguna razón -y ojalá no por sobrecarga extrema de trabajos como lo intentó Goldberg- podamos vivir de esto, de esta práctica amateur a la que se dedica la noche, los fines de semana. Práctica, como dice 
Stiegler, orientada por la pasión y el cariño y no por la posesión ni el consumo, práctica, también, en la que se pone formación, experiencia, dedicación, subjetividad, cariño, a la que se le asigna un propósito.

Así llego al otro tema o pregunta que anticipaba un poco más arriba, ¿cómo se le asigna un valor material a esta serie de preparaciones intangibles, sutiles que forman a un traductor, a la manera en que se acerca al texto? ¿Hay alguna manera en que se pueda vivir de la práctica, hacerla profesión, como intentó Goldberg, y al mismo tiempo mantener el deseo, la libertad, el sentido, como lo hizo Blackwell? La verdad es que no tengo una respuesta definitiva para dar. Tal vez habría que partir por plantear de nuevo la relación entre profesionales de las letras y traductores literarios o amateurs, entenderlos no como polos extremos de una ecuación sino como elementos de un diálogo, tal vez habría que lograr sacar a la traducción de los márgenes del campo literario, hacerla visible como una escritura más, o tal vez tendríamos que esperar la llegada de un nuevo sistema que suceda e incinere al capitalismo y su manera de generar márgenes, bordes, sombras donde circula tanta gente, tantas ideas, tanta cultura, afecto, y un largo, demasiado largo, etcétera.

\section{Lo que nos rodea}

Mi inquietud personal por la traducción, por sus condiciones y futuro, se fue expandiendo hasta llevar buena parte del foco de la investigación hacia el terreno del panamericanismo: sus comienzos, su desarrollo, su fracaso. ¿Cuál era el lugar de la traducción en estos escenarios? ¿Qué es lo que se quería llevar desde una región a la otra de acuerdo a las ideas del panamericanismo? ¿Qué era lo que querían comunicar los traductores? La razón de este desplazamiento, de esta llegada al panamericanismo, se debe a que es en torno a él que la compleja relación traductora entre Estados Unidos y Latinoamérica toma un impulso significativo y a que a través de su retórica se estableció un marco desde el que Estados Unidos leyó a América Latina y desde el que Latinoamérica pudo también reconocer la mirada estadounidense sobre la región. Como ya hemos dicho, la práctica de la traducción solo puede ser entendida si consideramos su interacción con las condiciones que la rodean. En el caso de Blackwell y Goldberg esas condiciones estuvieron moduladas en gran parte por las ideas del panamericanismo, las que planteaban lecturas reduccionistas sobre Latinoamérica, pero que de todos modos hicieron sentir su influencia tanto en la creación de políticas estadounidenses para con Latinoamérica como en la definición del intercambio cultural entre las regiones. En este sentido, la necesidad de acumular conocimiento acerca de los vecinos latinoamericanos que se hizo moneda corriente en la academia norteamericana 
dedicada en estos años al estudio de la región, marcó de manera particular el acercamiento a la literatura producida en las repúblicas del sur. Esta instrumentalización de la literatura llevó también al intento de instrumentalizar las pocas traducciones que se hacían entonces. La exploración del pedido de utilidad, de servicio, por parte del panamericanismo hacia la práctica de traducción, nos ayudó a revelar una cualidad esencial de la misma: su naturaleza amateur. Es desde ella que la tensión entre la práctica de la traducción y las propuestas del panamericanismo se hacen más evidentes. Se puede leer en la práctica de Blackwell el choque entre el proyecto hegemónico y la naturaleza deseante, resistente, del amateur, que en este caso identificamos como la del traductor literario.

Blackwell y sus traducciones, las que hace por deseo, no por dinero, y con la libertad de elegir qué traducir y cuándo hacerlo -todas características del amateurismo-, no son del todo funcionales para el proyecto panamericano, ordenado, mercantil, jerárquico. Ella no informa, no transmite hechos, datos, que es lo que pide el panamericanismo desde su necesidad de acumular conocimiento sobre Latinoamérica y sus habitantes. La inclinación de la traductora por la poesía también es un problema para la necesidad de información que plantea el panamericanismo y que se sirve mejor de la novela, de los hechos e información que esta pueda proveer. Por otra parte, la formación autodidacta de Blackwell, hace que prescinda de las instituciones donde se profesionaliza el estudio de las letras y lenguas al mismo tiempo que se asienta la idea del panamericanismo. Además, está su ser mujer, que también la tensiona en relación con un proyecto formulado y propagado por una elite de hombres blancos. Blackwell, entonces, como toda amateur, es un sujeto de los márgenes que produce bienes culturales que circulan, pero se mantienen en los bordes del sistema productivo capitalista, tal y como la misma traducción se queda en los bordes de la literatura. Aun así, la amateur, Blackwell, pone a circular bienes culturales. Su deseo la pone en movimiento, a ella y a lo que produce desde ese deseo: traducción, literatura. Podemos decir entonces, como una de las conclusiones centrales de este trabajo, que el amateur movido por su deseo, su cariño, su amor, es una molestia, un engranaje quebrado en la maquinaria del sistema capitalista o de un proyecto como el panamericanismo. Si este establecía un marco en el que se entendía a las “Américas” como un territorio común, propicio para la expansión de los mercados, es decir, para la racionalización de las relaciones económicas, Blackwell, que circulaba dentro y fuera, por los márgenes del proyecto panamericano, era una pequeña piedra en el zapato. Esto, porque la misma idea del amateur conspira contra la expansión de las relaciones de mercado y porque la traducción, como ella la practicaba, no servía como instrumento del panamericanismo. 
Blackwell y Goldberg, ¿tienen éxito en su distribución de bienes culturales originados en Latinoamérica? Sí y no. Sí, en cuanto logran lectores, traen a su lengua obras, miradas, que no existían antes. No, porque la circulación de sus traducciones es escasa y porque no consiguen crear esa unidad hemisférica de almas o de mentes que estos traductores piensan con urgencia a partir de las ideas del panamericanismo y de la rígida mirada que instala sobre Latinoamérica.

El panamericanismo ha presentado a Latinoamérica como territorio a modernizar mediante la expansión del capitalismo y, consecuentemente, de la influencia política de Estados Unidos. Un territorio conquistable entonces, no siempre por la intervención directa sino también por la hegemonía del poder político y económico. Esta idea de dominación arraigada en los orígenes mismos del panamericanismo se enfrentaba a otra característica de la traducción, la de su cosmopolitismo cultural. La capacidad de los traductores de posicionarse fuera de su cultura, su patria, su lengua, la idea de esta comunidad de mentes o de almas, de intelectos afines que se reúnen en un lugar intangible, entra en conflicto con la cualidad hegemónica, nacionalista, de un proyecto como el panamericanismo. Las opciones de un traductor ante un escenario así son escasas: puede colaborar con el proyecto hegemónico que impera en su contexto, transando su deseo, puede también, desde su margen, anotar, comentar, resistir el desequilibrio de poder entre las lenguas y las culturas a las que intenta comunicar, puede fracasar en el encuentro -no encontrar editoriales para sus textos, quedarse fuera de la circulación de productos culturales-, o perderse aun más en los márgenes. Estas tensiones entre la práctica de la traducción, el amateurismo que la conforma y los requisitos del proyecto hegemónico de turno, se renuevan en cada contexto, en cada nuevo escenario de traducción. Tal vez con el estudio detallado de estas tensiones y confrontaciones en distintos escenarios históricos, políticos, materiales, logremos entender mejor nuestra práctica, las búsquedas de Blackwell, de Goldberg y de todos quienes hemos venido detrás haciéndonos las mismas preguntas, agregando aristas nuevas mientras deseamos y escribimos nuestras versiones de un texto o de una voz que queda lejos y cerca, en la otra orilla del triángulo que avanza incesante en todo proceso de traducción. 
